\title{
Cenas de leitura em Silviano Santiago
}

\author{
Reading scenes in Silviano Santiago
}

Escenas de lectura en Silviano Santigo

Kelvin Falcão Klein*

\section{Resumo}

O objetivo do artigo é refletir acerca do papel da leitura na obra de Silviano Santiago. A primeira seção do trabalho é dedicada a apresentar um panorama dos usos da leitura e da figura do leitor em Silviano Santiago, tanto em sua obra ficcional quanto em sua obra ensaística, salientando a importância dos processos afetivos na escolha e no uso das referências literárias e teóricas (Graciliano Ramos, Barthes, Althusser). A segunda seção lida mais especificamente com o ensaio de Santiago "A vida como literatura" (2006), analisando as estratégias do autor no que diz respeito à sua leitura da obra de Cyro dos Anjos e sua peculiar problematização da vivência da subjetividade na leitura e na escritura, algo que é feito a partir do uso do significante "Silviano", tanto como nome próprio do autor quanto como personagem de Cyro dos Anjos. Por fim, o artigo se deterá em uma entrevista de Silviano Santiago de 2004 na qual ele apresenta como tarefa de leitura a obra do escritor alemão W. G. Sebald. Diante desse posicionamento declarado como leitor e do estabelecimento dessa cena de leitura, busca-se investigar a presença dos procedimentos ficcionais de Sebald no último romance de Silviano Santiago, "Machado", de 2016. Ao apresentar a figura do leitor como um ponto de atravessamento de diferença e repetição, Silviano Santiago faz do contato entre leitura e escritura uma performance de reconfiguração da tradição e das referências contemporâneas.

Palavras-chave: leitura, literatura brasileira contemporânea, Silviano Santiago, W. G. Sebald.

\section{Abstract}

The objective of this article is to reflect on the role of reading in the work of Silviano Santiago. The first section of the paper is devoted to presenting an overview of the uses of reading and the figure of the reader in Silviano Santiago, both in his fiction and essays, emphasizing the importance of affective processes in the choice and use of literary and theoretical references (Graciliano Ramos, Barthes, Althusser). The second section deals more specifically with Santiago's essay "Life as Literature" (2006), analyzing the author's strategies regarding his reading of the work of Cyro dos Anjos and his peculiar problematization of the experience of subjectivity in reading and in writing, which is made possible by the use of the signifier "Silviano", both as the author's own name and as a character of Cyro dos Anjos. Finally, the article will analyze an interview of Silviano Santiago in 2004 in which he presents the work of the German writer W. G. Sebald as required reading. Faced with this stated position as a reader and the establishment of this reading scene, we seek to investigate the presence of Sebald's fictional procedures in the last novel of Silviano Santiago,

\section{Resumen}

El objetivo del artículo es reflexionar acerca del papel de la lectura en la obra de Silviano Santiago. La primera sección del trabajo está dedicada a presentar un panorama de los usos de la lectura y de la figura del lector en Silviano Santiago, tanto en su obra ficcional como en su obra ensayística, subrayando la importancia de los procesos afectivos en la elección y el uso de las referencias literarias y teoréticas (Graciliano Ramos, Barthes, Althusser). La segunda sección trata más específicamente con el ensayo de Santiago "La vida como literatura" (2006), analizando las estrategias del autor en lo que se refiere a su lectura de la obra de Cyro dos Anjos y su peculiar problematización de la vivencia de la subjetividad en la lectura y la escritura, algo que se hace a partir del uso del significante "Silviano", tanto como nombre propio del autor como como personaje de Cyro dos Anjos. Por último, el artículo se detendrá en una entrevista de Silviano Santiago de 2004 en la que presenta como tarea de lectura la obra del escritor alemán W. G. Sebald. Ante este posicionamiento declarado como lector y del establecimiento de esa escena de lectura se busca investigar la

\footnotetext{
* Professor de Literatura Comparada na Escola de Letras da Universidade Federal do Estado do Rio de Janeiro (UNIRIO), Rio de Janeiro, RJ, Brasil. Dorcid.org/0000-0002-8997-1174. E-mail: kelvin.klein@gmail.com.
} 
Machado (2016). In presenting the figure of the reader as a point of convergence of difference and repetition, Silviano Santiago makes the contact between reading and writing a performance of reconfiguration of tradition and contemporary references.

Keywords: reading, contemporary Brazilian literature, Silviano Santiago, W. G. Sebald. presencia de los procedimientos de Sebald en la última novela de Silviano Santiago, "Machado", de 2016. Al presentar la figura del lector como un punto de atravesamiento de diferencia y repetición, Silviano Santiago hace del contacto entre lectura y escritura un performance de reconfiguración de la tradición y de las referencias contemporáneas.

Palabras clave: lectura, literatura brasileña contemporánea, Silviano Santiago, W. G. Sebald.

\section{Raízes e labirinto de um leitor}

Revisitando a obra de Silviano Santiago em busca do tema da leitura, percebo que ele é constante, seja em obras de viés mais ficcional, como Stella Manhattan (1985), seja em obras ensaísticas, como As raízes e o labirinto da América Latina (2006). Todo gesto de abertura será, portanto, arbitrário e substituível, além de operar dentro de um campo que tem recebido atenção nos últimos anos (ver, por exemplo, Silva, 2016). Diante disso, escolho a "Nota prévia" que abre Uma literatura nos trópicos, de 1978, por conta do caráter já canônico desse livro na universidade brasileira. A nota faz o diagnóstico de uma mudança de paradigma na atuação do "intérprete", que perdeu "a segurança no julgamento" e que agora sabe que seu trabalho é o de "saber colocar as ideias no devido lugar", "abrindo o leque de suas possibilidades para o leitor". O intérprete é, em suma, continua Silviano Santiago, "o intermediário entre texto e leitor, fazendo ainda deste o seu próprio leitor"; procura, por fim, "formalizar e discutir, para o curioso, os problemas apresentados pela obra, deixando com que esta se enriqueça de uma camada de significação suplementar e que aquele encontre trampolins menos intuitivos para o salto de leitura". A interpretação, portanto, é uma atividade que vai de uma leitura a outra, enriquecendo a obra com uma "camada de significação suplementar" no processo (Santiago, 2000, p. 7).

É fundamental também reter a noção de "salto de leitura" proposta rapidamente pelo autor na nota prévia. A metáfora do salto, que pode ser rastreada em Nietzsche ou Walter Benjamin, ${ }^{1}$ serve para marcar a leitura como atividade que não se quer totalizante ou esgotadora, e sim como movimento de abertura à diferença e o diálogo. A partir de Jacques Derrida e Roland Barthes, já no primeiro ensaio de Uma literatura nos trópicos ("O entre-lugar do discurso latino-americano"), surge a reivindicação da leitura que, "em lugar de tranquilizar o leitor, de garantir seu lugar de cliente pagante na sociedade burguesa", "o desperta, transforma-o, radicaliza-o e serve finalmente para acelerar o processo de expressão da própria experiência" (Santiago, 2000, p. 20). Adiante, já no fim do ensaio, surge a ênfase em um método de leitura especificamente latinoamericano: o escritor dessa região "lê o tempo todo e publica de vez em quando"; "a técnica de leitura e de produção dos escritores latino-americanos parece com a de Marx, de que nos falou recentemente Louis Althusser" (Santiago, 2000, p. 25-26). Marx lê Quesnay, Smith e Ricardo de forma tensa e suspeita, como devem fazer os latino-americanos com os europeus. O corolário dessa cena compartilhada de leitura é que a crítica deve descondicionar o leitor, "tornar impossível sua vida no interior da sociedade burguesa e de consumo" (Santiago, 2000, p. 26).

Retendo esse método latino-americano salientado no ensaio citado (que é de 1971), proponho um salto em direção a As raizes e o labirinto da América Latina, de 2006, livro que reitera e reconfigura tal método. Aqui também há uma nota prévia na qual o autor declara que faz homenagem a Sérgio Buarque de Holanda e a Octavio Paz, "intérpretes da América Latina", e especifica: "a leitura que se faz de Raizes do Brasil e de El laberinto de la soledad,

\footnotetext{
1 "Contra a ideia de uma totalidade sistemática de um pensamento que se desenrola a partir de si mesmo e chega, por uma série contínua de deduções, à sua realização e completude, Benjamin insiste nos momentos de descontinuidade, de salto, de interrupção, nas lacunas e nos rasgos do real e do pensar, momento que, na linguagem poética, a cesura configura" (Gagnebin, 2007, p. 90).
} 
provocadores do nosso título, é contrastiva e didática. [...] importa-lhe menos a erudição disciplinar; importa-lhe mais a perspectiva de análise. A metodologia de leitura" (Santiago, 2006, p. 9). Já de início o projeto se apresenta como uma leitura que corresponde a uma metodologia precisa. Não se trata de esgotar as especificidades de cada obra em uma perspectiva histórica ou mesmo sociológica, e sim produzir um contraste, instaurar uma perspectiva - ou seja, uma nova posição de observação da tradição. Colocando novamente Jacques Derrida em uso, Silviano Santiago chama seu projeto de leitura contrastiva de "narrativa", na qual "a subjetividade do escritor se oferece como consistência inconsciente ao leitor", estabelecendo uma relação significante entre as referências (Sérgio Buarque de Holanda e Octavio Paz) que é produzida pela leitura crítica (Santiago, 2006, p. 88).

Além disso, o texto propõe uma leitura crítica da Carta de Pero Vaz de Caminha pelo viés gramatológico de Derrida, mostrando como o sistema semântico instaurado pelo verbo plantar repercute tanto na experiência portuguesa quanto na espanhola. ${ }^{2} \mathrm{~A}$ leitura da Carta da parte de Silviano Santiago se articula a contrapelo de uma série de leituras anteriores, especialmente a de Sérgio Buarque de Holanda, mas também a aparentemente neutra leitura de Sílvio Batista Pereira no Vocabulário da carta de Pero Vaz de Caminha, de 1964. A própria leitura proposta por Silviano Santiago da Carta é um evento que se dá no tempo e que sofre arranjos e modificações. Retornando ao livro de 1978, Uma literatura nos trópicos, especificamente ao último dos ensaios, "Análise e interpretação" (publicado originalmente em 1975), encontramos algumas das referências elencadas até o momento. Em primeiro lugar, o autor retoma Louis Althusser e seu texto sobre as leituras de Marx, agora indicando a fonte, que não era informada em "O entrelugar do discurso latino-americano" (Lire le Capital). Os críticos literários, escreve Silviano Santiago, pegam de empréstimo a noção de leitura sintomal que Althusser desenvolve a partir de Marx: a leitura que se dá nos lapsos do texto lido, em suas lacunas, desvendando o indesvendável e armando um segundo texto que corre em paralelo ao primeiro (Santiago, 2000, p. 207).

Na sequência do resgate de Althusser, neste ensaio de 1975, surge também a Carta de Pero Vaz de Caminha, requisitada por conta da exposição da noção de "intertextualidade" e do atravessamento de textos no tempo e no espaço: "Tomando como exemplo os poemas de Oswald de Andrade da 'História do Brasil' (na coletânea Pau-Brasil), pode-se dizer que o autor da Carta de Pero Vaz Caminha seria tanto este quanto o poeta paulista, os dois, na medida em que um se inscrevia dentro do outro e vice-versa"; com isso, abandona-se "também uma visão cronológica e unívoca do estudo do texto literário ou cultural de modo mais geral", pois "retomar o texto histórico do cronista" e "apropriá-lo dentro de uma estética do nãosério, do jocoso, é operar um mecanismo de renversement ideológico, que pode ser explicado pela coexistência no mesmo momento escritural de afirmações que se contradizem" (Santiago, 2000, p. 209). Esse tipo de detalhe é o que dá densidade à tessitura de um texto, e muitas vezes só pode ser percebido a partir da convivência intensa com um livro e com os múltiplos fragmentos (não necessariamente coordenáveis ou articuláveis com relação a um todo) que o formam, revisitando-o e relendo-o com vagar.

Nota-se que a reflexão acerca da leitura da Carta de Caminha, no ensaio de 1975, ainda é muito colada ao uso específico que dela faz Oswald. Ao mesmo tempo, porém, reforça a ideia da leitura como fator "descondicionante" (anunciada no ensaio sobre o entre-lugar), agora a partir da noção de "renversement ideológico". Mas a aproximação aqui do ensaio de 1975 com o livro de 2006 mostra a Carta de Caminha como laboratório privilegiado dessa metodologia peculiar de leitura

\footnotetext{
3 "Do mesmo modo como em El laberinto de la soledad, o pachuco configura a singularidade neocolonial do mexicano na América Latina da segunda metade do século 20, a organização gramatológica da Carta de Pero Vaz de Caminha tem na semente o modo como ela configura a singularidade colonial portuguesa nos trópicos, tal como Raízes do Brasil ainda a discutirá quatro séculos depois pela metáfora do semeador como colonizador. Tanto o vocábulo pachuco quanto o vocábulo semente são exemplo de indecidível (indécidable). A decisão sobre o significado de um e do outro estará sendo operada pela máquina textual de diferenciação de Octavio Paz (o labirinto como produto da segunda máquina de diferenciação) e a de Sérgio Buarque (as raízes como produto da primeira máquina)" (Santiago, 2006, p. 89). Quanto à dimensão pós-colonial da reflexão de Silviano Santiago, central em As raízes e o labirinto da América Latina, é produtiva a consulta aos ensaios "Formações do sujeito colonial: suplemento, dependência, cosmopolitismo", de João Camillo Penna (2012, p. 295-306), e "Entre o presente e o inadiável: considerações sobre o pensamento de Silviano Santiago", de Heloisa Gomes (2014, p. 49-60).
} 
desenvolvida e defendida por Silviano Santiago. É preciso ainda mencionar que a Carta de Caminha faz outras duas aparições importantes na produção do autor: em setembro de 1998, Santiago apresenta a conferência "Destinos de uma carta" no Congresso 1498-1998: Raízes, Rotas e Reflexões, na Universidade do Minho, depois incluída no livro Ora (direis) puxar conversa! (Santiago, 2006a, p. 229-246); e em setembro de 2014 publica na Folha de S. Paulo o ensaio "Anatomia da formação", uma longa retrospectiva da sua carreira que lida majoritariamente com suas leituras da Carta de Caminha (Santiago, 2014, p. 4-5). ${ }^{3}$

\section{A vida como literatura}

Um ponto fundamental no que diz respeito à investigação da "cena de leitura" na obra de Silviano Santiago é seu uso de Graciliano Ramos no livro Em liberdade, de 1981. O projeto dessa ficção é colocar em prática a leitura ativa que se torna escritura de Roland Barthes - comentada no ensaio sobre o entre-lugar: "os outros textos, os escrevíveis, apresentam ao contrário um modelo produtor (e não representacional) que excita o leitor a abandonar sua posição tranquila de consumidor e a se aventurar como produtor de textos" (Santiago, 2000, p. 19). A premissa que sustenta Em liberdade é que Graciliano Ramos teria produzido um original com o mesmo título, entregue a um amigo em 1946 com o pedido que só fosse publicado vinte e cinco anos após sua morte. Em 1952, Graciliano muda o pedido e determina que o original seja queimado - o amigo, no entanto, não o faz. Ainda nessa "nota do editor" que abre Em liberdade, Silviano Santiago diz que recebeu o original em 1965, da viúva do amigo de Graciliano: "Conservei em segredo, até hoje, os originais de Em liberdade. Resolvo agora publicá-los, obedecendo ao prazo de vinte e cinco anos exigido pelo romancista", escreve ele, e continua: "Apenas uma coisa pediu-me o legítimo dono dos originais: que seu nome não fosse revelado. Tinha medo do julgamento da História quanto ao seu ato. Acatei o pedido. Portanto, toda a responsabilidade desta publicação recai sobre este, que assina, Silviano Santiago" (Santiago, 1982, p. 13).

Sobre Em liberdade, Silviano Santiago registra o seguinte em entrevista a Jorge Wolff em maio de 2000:

Em liberdade, por exemplo, é um romance e não é, é uma biografia e não é, é um ensaio e não é. Porque, analisando de perto Em liberdade, é um romance, é uma proposta de romance a partir do pastiche, é pós-moderno, etc etc. De outra perspectiva, é uma biografia, porque tudo aquilo aconteceu mais ou menos, quer dizer, eu tive um trabalho enorme de levantamento de dados, etc. E poderia ser uma biografia, eu poderia ter escrito uma biografia de Graciliano Ramos naquele período. Mas não é, porque obviamente eu inventei diálogos, eu inventei situações, apesar de partir de casos, de dados concretos. [...] Então eu acho que é a noção de limite, que é o que tem me salvado: eu estou sempre no limite dos gêneros (Wolff, 2016, p. 174).

Faltou acrescentar que a biografia não precisa necessariamente ser a biografia de Graciliano Ramos, mas desse leitor atento que toma para si a responsabilidade da escritura e que assina ao final da "nota do editor" de Em liberdade (e que anuncia a própria assinatura, como se colocasse o próprio ato da assinatura em ação na escritura), Silviano Santiago. Assim como está "sempre no limite dos gêneros", Santiago está sempre no limite do nome (próprio e alheio, e na zona cinza entre os dois). Em um breve livro de 2006, A vida como literatura, sobre o Amanuense Belmiro de Cyro dos Anjos, o autor retorna à questão do nome - e aqui, mais especificamente, à questão do nome falso.

\footnotetext{
${ }^{3}$ A Carta de Caminha surge em outros momentos da obra de Silviano Santiago; contudo, para encerrar, gostaria de citar também seu resgate em um ensaio reunido na coletânea Vale quanto pesa, originalmente de 1982, intitulado "Liderança e hierarquia em Alencar", uma vez que o autor não só retorna a Caminha como o faz a partir da mesma referência ao Lire le Capital de Althusser, usado nos ensaios de Uma literatura nos trópicos mencionados: "Somente uma leitura 'sintomal' da Carta, para usar o termo e o método de Althusser, devidamente alicerçada em um instrumental tomado de empréstimo à Antropologia, é que se poderá ir revelando todos os valores indígenas que se encontram recalcados no texto português" (Santiago, 1982, p. 91). A exposição desses retornos mostra que a produtividade da leitura está em sua metamorfose contínua em releitura. No que diz respeito à "leitura sintomal" de Althusser, é preciso remeter às elaborações bastante pertinentes de Michel Pêcheux - ver, por exemplo, Semântica e discurso (Pêcheux, 1997).
} 
A epígrafe de A vida como literatura é retirada de um livro publicado pelo escritor argentino Ricardo Piglia em 1975, Nombre falso, uma homenagem ficcional a Roberto Arlt bastante aparentada àquela que faz Silviano Santiago a Graciliano Ramos em 1981. O anúncio de uma filiação que se dá em 1981 (Em liberdade) mas que permanece recalcada até fazer sua emergência em 2006 (A vida como literatura). "Tenho o mau gosto de estar maravilhado por ser Roberto Arlt", escreve Ricardo Piglia, indicado na epígrafe de A vida como literatura (Santiago, 2006b, p. 6). Piglia, leitor de Arlt, se apropria do nome próprio deste último em 1975; Silviano Santiago, leitor de Graciliano Ramos, repete o procedimento em 1981; e, finalmente, em 2006, em A vida como literatura, é o nome próprio "Silviano" que é posto em questão, agora na leitura que se faz de Cyro dos Anjos. Pois "Silviano" é, simultaneamente, personagem de Cyro dos Anjos e assinatura de autor de Silviano Santiago: "Belmiro lê o multifário Silviano e este - clicado de uma outra e inusitada perspectiva - passa a representar dentro do romance o artista por excelência, e é nessa condição segunda, condição essencialmente nietzschiana, que ele traz a chave do livro" (Santiago, 2006b, p. 54). Duas páginas adiante, completa: "No universo ficcional de $O$ amanuense Belmiro, Silviano representa aquele que busca a verdade poética da vida. [...] Silviano é o grande personagem nietzschiano da literatura brasileira", acrescentando a torção autobiográfica: "Será preciso esperar cinquenta anos para que ele retorne num outro diário íntimo, numa outra ficção, fecundada por anos e anos de vida. [...] No seu retorno em 1980, Silviano estará travestido de certo Graciliano Ramos ao sair da prisão do Estado Novo nos primeiros dias de 1937" (Santiago, 2006b, p. 56-57).

O uso do nome próprio "Silviano" por Cyro dos Anjos é o que serve de mote a Silviano Santiago para, na escrita de A vida como literatura, resgatar também o projeto de Em liberdade. É no atravessamento tenso entre leitura e escritura (vida e obra, eu e outro) que se instaura uma nova perspectiva crítica, defende Santiago, uma perspectiva que servirá para reler "duas outras fascinantes e notáveis memórias imaginárias" cristalizadas em outros dois nomes próprios: "Brás Cubas" e "João Miramar" (Santiago, 2006b, p. 57). Uma leitura que coloque o nome próprio em questão, portanto, deve descondicionar e reconfigurar, na própria extensão de seu gesto, os planos futuros do artista e do crítico.

\section{Ler mais e melhor}

Depois do percurso apresentado, é possível resgatar agora um questionário respondido por Silviano Santiago para o terceiro número da revista Outra travessia, de 2004. O intuito é o de perceber como Santiago fala da leitura, da necessidade da leitura e como isso se impõe como uma atividade crítica, uma autoimposição de obstáculos e questões. Não se trata da leitura tal como entendida pelo senso comum, mas essa leitura que os escritos de Santiago evidenciam - feita a partir de uma perspectiva descondicionada, do viés de uma vida que se tornou impossível no interior da sociedade burguesa e de consumo (Santiago, 2000, p. 26). O mesmo questionário foi enviado para Noé Jitrik, Silviano Santiago, Raul Antelo, Doris Sommer, Eneida Maria de Souza, Diana Sorensen e Heloísa Buarque de Hollanda, e o conjunto das respostas foi publicado em Outra travessia. Era composto das seguintes questões:

1) Que tipos de influências teóricas você considera importantes para a configuração do trabalho crítico que você vem realizando?

2) Qual é o seu projeto de investigação pessoal neste momento?

3) Quais as leituras que está fazendo atualmente?

4) Em sua opinião seria interessante a existência de uma crítica literária e cultural de âmbito latino-americano? Por quê?

5) O que você pensa das discussões realizadas nas últimas três décadas pela crítica literária sobre os estudos culturais, de gênero, de transdisciplinaridade? (Jitrik et al., 2004, p. 7).

A resposta de Silviano Santiago é única, abarcando as cinco questões em um fluxo de resposta que, como não poderia deixar de ser, coloca ênfase na figura do leitor crítico. Glosando a noção problemática de "influência", ele escreve que a "contribuição propriamente brasileira (ou 
marginal, no sentido cultural e amplo da palavra)" ao debate teórico "tende a ser silenciosa e secreta" e "os próprios leitores brasileiros (falo dos meus) muitas vezes só são capazes de enxergar a dívida e, raramente, muito raramente, a retribuição crítica que, no entanto, está clara para o leitor de espírito mais apurado, cujas coordenadas foram devidamente descentradas do conceito de influência" (Jitrik et al., 2004, p. 11). Cabe dizer que identifico tal "retribuição crítica" - sugerida por Silviano Santiago em sua resposta - precisamente no movimento que envolve a leitura crítica e a requisição do nome próprio esboçada logo acima neste ensaio (a partir do salto que aproxima Em liberdade e A vida como literatura). Ele ainda especifica em sua resposta: "Raciocino, imagino, leio, escrevo em meio a um fogo cruzado e cerrado, que qualifiquei de entrelugar", um "território bélico" que é tanto "biográfico" quanto "artístico", numa "rica concomitância de tempos e espaços" (Jitrik et al., 2004, p. 12).

A continuidade da resposta aprofunda a exposição do método de leitura: Santiago se apresenta como um "leitor público", alguém que tenta se manter atualizado com "jornais e revistas", "nacionais e internacionais", lendo-os "praticamente todos os dias"; dá o contexto de uma situação precisa, ou seja, a releitura, "nos últimos três ou quatro meses", de grande parte da obra de Clarice Lispector e "alguns ensaios sobre ela", além do Prazer do texto, de Barthes, e algumas obras de Nietzsche e Jacques Derrida; a última indicação direta de leitura na resposta merece um desenvolvimento e diz respeito ao livro L'aperto, de Giorgio Agamben, "um verdadeiro deslumbramento", dizendo ainda que "há muito não aparecia um livro tão fascinante sobre o saber-literário", reunindo Rilke, Heidegger e Georges Bataille (Jitrik et al., 2004, p. 13). Por fim, Silviano Santiago aponta uma lacuna; ou melhor, escolhe encerrar esse segmento de sua resposta - que lida diretamente com o compromisso da leitura - com um diagnóstico que sintomaticamente se posiciona no futuro do pretérito: "Gostaria de ter mais tempo para ler mais e melhor os livros de G. W. Sebald" (Jitrik et al., 2004, p. 13). A expectativa da leitura e a ação do leitor parecem nesse momento repercutir a conhecida intuição de Walter Benjamin acerca da tradução, que é tanto tarefa quanto renúncia (Seligmann-Silva, 2005, p. 171; Weber, 2008, p. 54-56). Mais uma vez Silviano Santiago opera no entre-lugar, agora entre o futuro e o pretérito, instaurando uma tarefa de leitura ao mesmo tempo em que estabelece uma (falsa) limitação de possibilidades.

\section{Machado}

Minha hipótese é a seguinte: a declaração de Silviano Santiago a respeito de W. G. Sebald no questionário de 2004 é o primeiro elemento de uma série que o leva à publicação de Machado, seu livro de 2016; além disso, gostaria de sugerir que Santiago lê Sebald à moda de Barthes e Althusser, ou seja, uma leitura crítica e criativa que busca reconfigurar e renovar o texto de partida tornando-se ela própria - a leitura - escritura, seguindo as lições dos ensaios do próprio Silviano de fins da década de 1970, conforme exposto na primeira seção deste artigo.

A menção de Silviano Santiago ao autor alemão na resposta ao questionário, contudo, parte de um sutil equívoco: escreve "G. W." ao invés de W. G. Sebald (Winfried Georg Sebald, 1944-2001). De origem alemã, Sebald se estabeleceu como professor na Inglaterra - em Norwich, na University of East Anglia - logo depois do doutorado, permanecendo lá até sua morte, em um acidente de carro, em 2001. Depois de uma série de publicações acadêmicas ao longo das décadas de 1970 e 1980, Sebald lança seu primeiro livro de ficção em 1988, o poema narrativo Nach der Natur - na tradução portuguesa de Telma Costa, Do natural (Sebald, 2012). Em 1990, lança seu primeiro romance, Schwindel. Gefühle, traduzido no Brasil como Vertigem: sensações (Sebald, 2008); em 1992, o segundo, Die Ausgewanderten, Os emigrantes (Sebald, 2009; 2002); em 1995, o terceiro, Die Ringe des Saturn, Os anéis de Saturno (Sebald, 2010); e, por fim, o quarto romance, Austerlitz, lançado em 2001 (Sebald, 2008a). O primeiro livro de Sebald, Do natural, apesar de fazer muitas referências a imagens (especialmente a pinturas do artista alemão Matthias Grünewald), não apresenta nenhuma reprodução, apenas texto. A partir de Vertigem, no entanto, todos os livros de Sebald virão com um grande número de reproduções de imagens ao longo das narrativas. 
As aproximações possíveis entre Machado, de Silviano Santiago, e a obra de Sebald em geral são várias. Em primeiro lugar, o referido uso das imagens intercaladas ao texto, operando como elementos essenciais para o andamento da narrativa. No caso de Sebald, as imagens são sempre em preto e branco e de fontes as mais diversas, desde reproduções de pinturas ou fotografias alheias, até fotografias tiradas pelo próprio Sebald, reproduções de fragmentos de jornal, de documentos, bilhetes de trem, desenhos, notas manuscritas, etc. No caso de Os emigrantes, por exemplo, são exatamente 79 imagens utilizadas (na edição da Record; a edição da Companhia das Letras tem 77, duas imagens a menos). Tirando a foto de capa de O falso mentiroso (Santiago, 2004), que mostra o autor quando bebê, Machado marca a primeira vez que Silviano Santiago usa imagens - e o faz de forma extensiva e cuidadosa, à maneira de Sebald (com uma diferença importante: Machado tem uma reprodução colorida, logo na primeira página, da tela "Transfiguração", de Rafael, do século XVI). ${ }^{4}$ E também à maneira de Sebald, as imagens usadas por Silviano Santiago são de naturezas as mais diversas: reproduções de trechos de cartas manuscritas, de notícias de jornal, de fotografias do século XIX e XX, de retratos de autores e capas de livros, índices de revistas, túmulos, cartões-postais, caricaturas, etc. No caso de Machado, são 65 imagens reproduzidas ao longo da narrativa.

Além disso, há uma afinidade pronunciada entre o narrador desenvolvido por Silviano Santiago em Machado e aqueles presentes nos livros de Sebald. No caso deste último, seus quatro romances são bastante regulares no que diz respeito ao narrador, que parece manter suas características principais de um livro a outro, fazendo inclusive referência a projetos anteriores. Os anéis de Saturno, por exemplo, inicia com a frase: “Em agosto de 1992, quando os dias de canícula chegavam ao fim, pus-me a caminhar pelo condado de Suffolk, no leste da Inglaterra, na esperança de escapar ao vazio que se alastra em mim sempre que termino um longo trabalho" (Sebald, 2010, p. 13). Com o andamento da narrativa, vários indícios são dados que mostram que esse "longo trabalho" terminado era o romance anterior de Sebald, Os emigrantes. O narrador de Sebald é sempre um acadêmico de origem alemã, estabelecido na Inglaterra, que de quando em quando separa um tempo para viajar e colocar no papel suas anotações acerca de seus deslocamentos, leituras e encontros com outros indivíduos. A narrativa de Sebald é sempre mesclada com digressões ensaísticas que atravessam campos como a história, a antropologia, a filosofia, a geografia, a arquitetura, entre outros.

Machado, por sua vez, ainda que se identificando como "romance" no subtítulo, é pontuado por digressões semelhantes às de Sebald - além de apresentar epígrafes em todo início de capítulo. Também em Machado o narrador é um pesquisador, alguém que incorpora ao ritmo de sua narração o olhar peculiar de um acadêmico, um intelectual que procura descondicionar seu olhar para o mundo, os textos e as biografias. A primeira frase do livro é a seguinte: "Compro o quinto volume da correspondência de Machado de Assis na manhã do dia 24 de junho de 2015" (Santiago, 2016, p. 13). É em torno da leitura desse volume que se organiza toda a narrativa de Machado, que vai se espalhando pouco a pouco à medida que segue os rastros encontrados nesse livro específico, adquirido nesse dia específico. Pode-se aqui recordar a citação de Os anéis de Saturno, de Sebald, feita no parágrafo anterior, salientando que também aí há uma menção específica de data - agosto de 1992, um procedimento que se repete em todos os inícios dos romances de Sebald. ${ }^{5}$ Esse procedimento de atenção à data é desdobrado por Silviano Santiago

\footnotetext{
${ }^{4}$ Silviano Santiago também faz uso da pintura "Ló e suas filhas", de Lukas van den Leyden, na contrapaca da primeira edição de seu romance Viagem ao México, que é comentado na narrativa: "O quadro de Lukas van den Leyden, entrevisto há quatro anos no Museu do Louvre, me levou a compreender a Bíblia de maneira diferente do modo como a compreendemos no nosso século e, por isso, ficara gravado de maneira indelével na minha memória: a história de Ló e as duas filhas não me saía da imaginação nas longas horas em que ficava deitado esperando o sono chgar" (Santiago, 1995, p. 134). Coincidentemente, Sebald também usa uma imagem de Ló e suas filhas em seu livro Do natural, de autoria de Albrecht Altdorfer, aproximando poéticamente a destruição de Sodoma da destruição de Nuremberg durante a II Guerra Mundial (Sebald, 2012, p. 81-82).

${ }^{5}$ Os livros de Sebald são sempre muito precisos, já em suas linhas iniciais, em localizar a história no tempo e no espaço. Além da já citada frase de abertura de Os anéis de Saturno, Vertigem, romance de 1990, começa com: "Em meados de maio de 1800, Napoleão e seus trinta e seis mil homens atravessaram o Grande São Bernardo, uma empreitada considerada até então como praticamente impossível" (Sebald, 2008, p. 7). Os emigrantes, de 1992, diz: "No final de setembro de 1970, pouco antes de assumir meu cargo em Norwich, no leste da Inglaterra, eu e Clara fomos de carro até Hingham em busca de um lugar para morar" (Sebald, 2009, p. 9). E Austerlitz, de 2001: "Na segunda metade dos anos 60, viajei com frequência da Inglaterra à Bélgica, em parte por motivo de estudos,
} 
em Machado já na continuidade do primeiro capítulo, quando menciona o "13 de janeiro de 1937", dia em que "o romancista Graciliano Ramos deixa a prisão a que fora condenado sem julgamento pelo regime Getúlio Vargas"; ou ainda, "a viagem em 1936 do dramaturgo francês Antonin Artaud ao México", duas referências que servem a um duplo propósito: remeter indireta e sutilmente o leitor de Machado a outros livros de Santiago (Em liberdade e Viagem ao México, respectivamente - este último publicado em 1995); marcar a proximidade desse narrador com o autor e nome próprio "Silviano Santiago"; e, por fim, estabelecer uma premissa ensaística de abordagem à figura de Machado de Assis.

No início do segundo capítulo de Machado (intitulado "29 de setembro"), o narrador retorna ao seu contato com o volume: "Uso as duas mãos como pinça e com elas imprenso e logo depois apalpo o grosso volume da Correspondência de Machado de Assis. [...] Manuseia-o como se fosse pequeno e misterioso embrulho explosivo, entrevisto ao acaso da caminhada rotineira pelas ruas antigas do centro do Rio de Janeiro" (Santiago, 2016, p. 48-49). Um aspecto fundamental aqui, e que será reiterado ao longo de todo o livro, é o entrelaçamento da figura do leitor com a figura do caminhante, daquele que deambula pela cidade, o flâneur. O narrador de Machado toma esse entrelaçamento como uma definição possível (e provisória) da própria subjetividade ao mesmo tempo em que reconhece o mesmo fenômeno em Machado de Assis - e, seguramente, também em W. G. Sebald. Assim como acontece em Machado, na obra de Sebald ocorre o mesmo entrelaçamento entre leitura e caminhada, uma articulação que é também projetada no tempo em direção a um personagem que se tenta apreender: Machado de Assis no caso de Silviano Santiago, Jacques Austerliz no caso de Sebald, especificamente em seu último romance publicado, Austerlitz, de 2001. Ao longo da narrativa, acompanhamos os encontros do narrador com esse personagem, Jacques Austerlitz, um professor universitário aposentado de História da Arquitetura, que descobre já adulto seu nome verdadeiro e sua origem familiar: ele foi enviado ainda criança da Tchecoslováquia para a Grã-Bretanha em 1939, para escapar dos nazistas.

Os encontros do narrador com Austerlitz se dão na rua, por vezes seguidos de caminhadas: "Enquanto me contava tudo isso, Austerlitz e eu fizemos o caminho de volta do cemitério atrás do hospital St. Clement's até a Liverpool Street" (Sebald, 2008a, p. 246). Quando começa a recordar o passado recalcado de sua infância - a partir de algo escutado no rádio -, Austerliz está dentro de um sebo, mexendo em livros e gravuras: "eu folheava distraidamente as diversas caixas e gavetas, fitava durante minutos uma abóbada em forma de estrela ou um friso em forma de diamante, uma ermida, um monóptero ou um mausoléu, sem saber o que eu fitava ou por quê" (Sebald, 2008a, p. 141). Em Machado, além do contato intenso do narrador com o volume das correspondências, Silviano Santiago também apresenta o próprio Machado de Assis devotado ao contato com um livro sobre o quadro "Transfiguração", de Rafael: "O tormento de Machado só se acalma no dia em que recebe das mãos de Magalhães de Azeredo, então em visita aos familiares no Rio de Janeiro, um exemplar do livro, com capa em cor esmaecida" (Santiago, 2016, p. 405). E o contato do narrador de Machado com o volume das correspondências se torna ainda mais pronunciado quando ele declara: "Transfiguro-me. Sou o outro sendo eu. Sou o tomo V da correspondência de Machado de Assis: 1905-1908" (Santiago, 2016, p. 49).

A noção de "transfiguração" é, aqui, fundamental, pois atravessa todas as operações de Silviano Santiago comentadas até aqui. Em Machado, trata-se da transfiguração de um leitor que se torna escritor e que move a escritura em direção a essa biografia e esse nome próprio que dá título ao romance, uma metamorfose que começa com esse contato entre o indivíduo e o "tomo V da correspondência de Machado de Assis". Além disso, há toda a transfiguração de Sebald operada por Silviano Santiago, da entrevista de 2004 ao romance de 2016, absorvendo e reconfigurando seus procedimentos, transformando Austerlitz em Machado, passando de Londres para o Rio de Janeiro, rearmando o cenário eurocêntrico do autor alemão em uma perspectiva que é tanto local quanto mundial e que opera em dois inícios de 
séculos, o XX e o XXI, o de Machado e o de Silviano Santiago. Resgatando o que foi exposto mais acima com relação ao livro A vida como literatura e o uso que Silviano Santiago faz do nome próprio (suas falsificações e desvios tanto de significado quanto de significante), é digno de nota que os dois romances em questão - Machado e Austerlitz - operem novamente na chave do questionamento do nome próprio e, consequentemente, do questionamento dos protocolos de leitura e escrita das vidas, das biografias e dos testemunhos. ${ }^{6}$

Quando o narrador de Machado afirma que é "transfigurado" em sua relação com o livro, também faz uma referência direta a essa imagem que abre o romance, o quadro de Rafael. A relação de Machado de Assis com essa imagem é o fio condutor de toda a narrativa, especialmente por conta da presença de um menino epilético no primeiro plano da pintura de Rafael. Consequentemente, essa relação será fundamental também para o narrador de Machado e seu comentário a respeito da relação de Machado de Assis com a "Transfiguração" (é fundamental perceber como o significante desliza, às vezes indicando o quadro de Rafael, às vezes indicando a relação do autor Machado com a pintura e a relação do narrador de Machado com a figura biografada, a pintura de Rafael e o tomo $V$ da correspondência). A noção de "transfiguração" também percorre todo o livro Machado em um sentido muito literal: como foi dito acima, a reprodução colorida do quadro de Rafael ocupa a primeira página do livro, logo depois da ficha catalográfica e antes da dedicatória, das epígrafes e do índice; por fim, o romance se encerra justamente com a discussão aprofundada do quadro e da relação de Machado de Assis com o quadro, uma reflexão mediada pelo livro recebido das mãos de Magalhães de Azeredo, Examen analitique du tableau de la Transfiguration de Raphael, de Benito Pardo, cuja folha de rosto é reproduzida (Santiago, 2016, p. 406).

É possível mencionar que um procedimento semelhante também é exercitado por Sebald, especialmente em seu romance Os anéis de Saturno. Logo na abertura da narrativa, nas primeiras páginas, o narrador de Sebald inicia uma digressão ensaística que o leva ao quadro $A$ Lição de Anatomia do Dr. Tulp, de Rembrandt, pintado em 1632. O foco é dado ao corpo morto do ladrão, que está sendo dissecado e observado pelos médicos ao seu redor: "pode-se deduzir do caráter cerimonial da mutilação do morto", escreve Sebald, "perceptível na representação de Rembrandt os cirurgiões vestem seus melhores trajes, o dr. Tulp está até mesmo com chapéu na cabeça", que "na lição de anatomia de Amsterdam se tratava de algo mais do que um melhor conhecimento dos órgãos internos do ser humano" (Sebald, 2010, p. 24). O narrador de Os anéis de Saturno encontra na imagem de Rembrandt uma crítica ao projeto racionalista de Descartes, seu contemporâneo, e reconhece isso no detalhe da representação da mão do cadáver: "A mão disforme é um sinal do poder que passou por Aris Kindt. O pintor compara-se a ele, à vítima, e não à guilda dos cirurgiões que lhe fez a encomenda. Ele é o único que não tem o olhar cartesiano fixo" (Sebald, 2010, p. 25). A aparição dessa imagem logo no início do romance faz com que as questões colocadas por ela reverberem ao longo da narrativa - sobretudo essa sutil mas contundente crítica aos projetos racionalistas e representacionais ocidentais (Gray, 2009, p. 495-526).

Boa parte do apelo estético de Machado está na reflexão acerca da relação de Machado de Assis com o quadro de Rafael e toda a elaboração da ideia de "transfiguração", seja a partir da leitura, da escrita, da epilepsia e da metamorfose conferida ao homem de letras através do reconhecimento. O encerramento do romance de Silviano Santiago se dá com o escritor diante da imagem: "Machado de Assis aprofunda os olhos no cartão-postal que reproduz a Transfiguração. [...] Em toda a tela, o Cristo, os profetas, os apóstolos e os familiares do rapaz epilético não falam. Exprimem-se por gestos, como mímicos" (Santiago, 2016, p. 415). Além disso, por conta do uso que Rafael faz da tradição e dos procedimentos artísticos, temas e

\footnotetext{
${ }^{6}$ Pode-se aqui recordar a reflexão de Giorgio Agamben sobre testemunho, nome próprio, subjetividade e heteronímia em $O$ que resta de Auschwitz, livro no qual ele articula Primo Levi a Fernando Pessoa a partir de uma reconfiguração das ideias de Emile Benveniste e Michel Foucault sobre a expressão da subjetividade no discurso: "Se, na relação entre o dito e o seu ter lugar, o sujeito do enunciado podia, realmente, ser colocado entre parênteses, porque o ato de tomar a palavra já havia ocorrido, a relação entre a língua e sua existência, entre a langue e o arquivo, exige, por sua vez, uma subjetividade como aquilo que atesta, na própria possibilidade de falar, uma impossibilidade de palavra. Por tal motivo, ela se apresenta como testemunha, pode falar por quem não pode falar. O testemunho é uma potência que adquire realidade mediante uma impotência de dizer e uma impossibilidade que adquire existência mediante uma possibilidade de falar" (Agamben, 2008, p. 147).
} 
motivos da Antiguidade, a reprodução da "Transfiguração" se torna, em Machado, uma metáfora da relação criativa do próprio Machado de Assis diante das referências e da tradição: "Rafael tem em vista a lição dos mestres da Antiguidade. Pensa Machado que o arcabouço clássico, que informa a escolha do tema bíblico e conforma a figuração objetiva dos personagens em ação nos seus romances, se deixa subverter pelos próprios sentimentos à flor da pele no seu cotidiano" (Santiago, 2016, p. 412). A reprodução do quadro de Rafael, que abre e fecha o romance Machado, se dissemina metaforicamente por toda a extensão da narrativa, servindo de trampolim e ampliando o leque de possibilidades de leitura.

Por fim, é preciso ressaltar que a principal transfiguração operada por Silviano Santiago em Machado é aquela que faz da obra de W. G. Sebald, retomando seus procedimentos, seu tom narrativo e seu uso das imagens, mas reconfigurando todos esses elementos a partir de uma perspectiva já estabelecida em sua obra pregressa. Transfiguração e contato que seguem em operação nesses mesmos termos ainda recentemente. Em ensaio sobre o período de Helio Oiticica em Nova York - na década de 1970, quando Silviano Santiago o conhece nos Estados Unidos por intermédio de Rubens Gerchman -, publicado em 2016 no número cinco da revista Peixe-elétrico e em 2017 na revista Ars (do Programa de Pós-Graduação em Artes Visuais da Escola de Comunicações e Artes da Universidade de São Paulo), Santiago cita mais uma vez Sebald, relacionando a representação do autor alemão de emigrantes ao próprio fluxo migratório brasileiro na época da ditadura (Santiago, 2017, p. 216). O contato entre Silviano Santiago e W. G. Sebald, anunciado na entrevista de 2004 e materializado no romance de 2016, oferece uma cristalização visível do complexo processo de articulação entre leitura e escritura. Ao apresentar a figura do leitor como um ponto de atravessamento de diferença e repetição, Silviano Santiago faz do contato entre leitura e escritura uma performance de reconfiguração da tradição e das referências contemporâneas - como é o caso certamente em seu contato com W. G. Sebald.

\section{Referências}

AGAMBEN, Giorgio (2008). O que resta de Auschwitz: o arquivo e a testemunha. Tradução de Selvino J. Assmann. São Paulo: Boitempo.

GAGNEBIN, Jeanne-Marie (2007). Da escrita filosófica em Walter Benjamin. In: SELIGMANN-SILVA, Márcio (Org.). Leituras de Walter Benjamin. São Paulo: AnnaBlume; Fapesp. p. 83-92.

GOMES, Heloisa Toller (2014). Entre o presente e o inadiável: considerações sobre o pensamento de Silviano Santiago. Cadernos de Estudos Culturais, Campo Grande, v. 6, p. 49-60.

GRAY, Richard T. (2009). From grids to vanishing points: W. G. Sebald's critique of visual-representational orders in “Die Ringe des Saturn”. German Studies Review, v. 32, n. 3, p. 495-526, out.

PÊCHEUX. Michel (1997). Semântica e discurso: uma crítica à afirmação do óbvio. Tradução de Eni P. Orlandi et al. Campinas: Editora da UNICAMP.

PENNA, João Camillo (2012). Formações do sujeito colonial: suplemento, dependência, cosmopolitismo. Revista ALEA, Rio de Janeiro, v. 14, n. 2, p. 295-306, jul./dez.

SANTIAGO, Silviano (2017). Hélio Oiticica em Manhattan. ARS (São Paulo), São Paulo, v. 15, n. 30, p. 207-216, out.

SANTIAGO, Silviano (2014). Anatomia da formação: a literatura brasileira à luz do pós-colonialismo. Folha de S. Paulo, São Paulo, Cardeno Ilustríssima, p. 4-5, 7 set.

SANTIAGO, Silviano (2006). As raízes e o labirinto da América Latina. Rio de Janeiro: Rocco.

SANTIAGO, Silviano (2006a). Ora (direis) puxar conversa!: ensaios literários. Belo Horizonte: Editora UFMG.

SANTIAGO, Silviano (2006b). A vida como literatura: O Amanuense Belmiro. Belo Horizonte: Editora UFMG.

SANTIAGO, Silviano (2004). O falso mentiroso: memórias. Rio de Janeiro: Rocco. 
SANTIAGO, Silviano (2000). Uma literatura nos trópicos: ensaios sobre dependência cultural. 2. ed. Rio de Janeiro: Rocco.

SANTIAGO, Silviano (1995). Viagem ao México. Rio de Janeiro: Rocco.

SANTIAGO, Silviano (1982). Vale quanto pesa: ensaios sobre questões político-culturais. Rio de Janeiro: Paz e Terra.

SANTIAGO, Silviano (1981). Em liberdade: uma ficção de Silviano Santiago. Rio de Janeiro: Paz e Terra.

SEBALD, W. G. (2012). Do natural: um poema elementar. Tradução de Telma Costa. Lisboa: Quetzal.

SEBALD, W. G. (2010). Os anéis de Saturno: uma peregrinação inglesa. Tradução de José Marcos Macedo, São Paulo: Companhia das Letras.

SEBALD, W. G. (2009). Os emigrantes: quatro narrativas longas. Tradução de José Marcos Macedo, São Paulo: Companhia das Letras.

SEBALD, W. G. (2008). Vertigem: sensações. Tradução de José Marcos Macedo. São Paulo: Companhia das Letras.

SEBALD, W. G. (2008a). Austerlitz. Tradução de José Marcos Macedo. São Paulo: Companhia das Letras.

SEBALD, W. G. (2002). Os emigrantes. Tradução de Lya Luft. Rio de Janeiro: Record.

SILVA, Maria Andréia de Paula (2016). Silviano Santiago: uma pedagogia do falso. Curitiba: Appris Editora.

SELIGMANN-SILVA, Márcio (2005). O local da diferença: ensaios sobre memória, arte, literatura e tradução. São Paulo: Editora 34.

WEBER, Samuel (2008). Benjamin's abilities. Cambridge, M.A.: Harvard University Press.

WOLFF, Jorge H. (2016). Telquelismos latino-americanos: a teoria crítica francesa no entre-lugar dos trópicos. Rio de Janeiro: Papéis Selvagens.

JITRIK, Noé et al. (2004). Entre miradas. Revista Outra Travessia, Florianópolis, n. 3, p. 7-38, jan. 